\title{
PRIORITY AREAS OF THE SMALL BUSINESS ACTIVATION IN UKRAINE
}

\author{
Larysa Poliatykina', Iryna Samoshkina² \\ Sumy National Agrarian University, Ukraine
}

\begin{abstract}
The purpose of the article is to summarize and highlight the key areas of activation of small business enterprises. The goal of the research is to obtain accurate and complete information that would enable to determine the objective and overall assessment of small business operation at the present stage of development of business relations in Ukraine; to identify impediments to their operation; to find reserves to improve the efficiency of small business operation. Problem statement. The research is aimed at studying the current state and determining the prospects of the small business development in Ukraine; analysing the deficiencies and formulating the main trends in the small business operation. In addition, the research goal is to examine the features of the creation, operation, and development of small businesses, and to go into the details of their basic challenges and specifics. Methodology. Analysis of small business operation and features of its conduct was carried out during the study. Issues of the formation and operation of the small business, as well as workflow management and business administration at these enterprises, are controversial. As a result of the study, the tendencies of the operation of small business enterprises are considered, the main problems and their solution in Ukraine are elucidated in detail. The crucial factor for the development of ent repreneurship in Ukraine is the formation of extensive infrastructure to support the development of small businesses. Efficient operation of this infrastructure contributes to the increased investment appeal of regions, the attraction of domestic and foreign investment, and the application of advanced technologies. Practical implications. It is noted that expedient is the work to ensure further development of small businesses and their relevance to the economic development of the country as a whole. Small businesses perform a variety of important economic and social objectives. They develop the real economy, increase employment opportunities, and promote competition. Therefore, the development of small business is the important task of the government. Value/originality. The analysis of the study conducted shows that the performance of the important economic and social role by small businesses is possible only due to the balanced state policy of comprehensive support for this sector of the economy. Therefore, the promotion of the small business development in Ukraine should be based on the implementation of the European experience that is based on the European standards of entrepreneurial development that will significantly contribute to the creation of a modern market economy with social justice.
\end{abstract}

Key words: small business, government support, entrepreneurship, investment, lending, competitiveness.

JEL Classification: R11, D21, O12, M21

\section{Introduction}

The efficient tool to facilitate the effective development of small businesses is the infrastructure of its support, due to which the specific organizational and economic environment is formed for the promotion of entrepreneurship and rapid adaptation of small businesses to market conditions. The global experience and business practice show that the most dynamic element of the national economic structure, which is constantly changing, is a small business.

Corresponding author:

${ }^{1}$ Department of Accounting, Sumy National Agrarian University.

E-mail: L.poliatykina@ukr.net

${ }^{2}$ Department of Finance, Sumy National Agrarian University.

E-mail: ira_samoshkina@ukr.net
Under the development of the Ukrainian economy, the strategic pathway to the creation of a competitive environment is the development of small businesses. Small businesses have been the focus of attention over the course of decades. Their activity is the multifaceted socio-economic phenomenon, where an entrepreneur or enterprise has the possibility of finding its level, and the external participants benefit as well. Despite a considerable number of scientific works on this subject matter, the problem of small business operation 
remains in abeyance, and plenty of issues concerning the development of small business in Ukraine call for further study.

At present, the development of small business in Ukraine is influenced by many factors, overarching of which may include a deficient legal framework; a lukewarm support from the governmental, regional agencies; the poor development of the infrastructure of sales, processing and storage of finished products; the lack of methodological support for the organizational and economic activities of small business.

A great deal of focus has been recently placed on the study of the issues of the small business organization and operation. The problems of justification and trends of the small business development are studied in the works of both domestic and foreign scientists. A significant contribution to the development of the theoretical foundations and methodological approaches to the solution of the above problems is reflected in the works of scientists-economists.

To ensure the Ukrainian economic recovery, it is expedient to reform agricultural enterprises and to consider all possible options for restructuring in order to adapt production operations to the business environment and to increase their competitiveness in appropriate conditions.

In this study, the pride of place is given to the problems of operation of small businesses, which are more resilient to external changes. Given a small number of employees quickly adjusting to market changes, a small business may turn out to be the important basis, on which a pivot towards the effective business processes will begin. These enterprises provide the socially vulnerable sections of the population, in particular, young people, women, immigrants, etc., with the possibility of employment. They also gain experience, knowledge, and enhance their career and self-fulfilment at these enterprises.

At the same time, the main objectives of the Ukrainian economic policy, as before, remain the achievement of economic growth and full employment, raising the living standards of the majority of the population, support for the national currency exchange rate, external equilibrium, etc. The achievement of these objectives is largely associated with the state of affairs and prospects of the small business development. These issues have not been addressed in full that predetermines the need for the scientific research aimed at the formation and development of entrepreneurship, its effective operation that will ensure the country's overcoming the protracted crisis. The important aspect of the impact of small business on the regional development is the solution to the problem of even distribution of business entities associated with the satisfaction of the population's effective demand.

The issues of the small business development at the branch level are not sufficiently addressed and require further study. However, a plenty of theoretical and practical aspects of using the potential of small business have not been settled yet.

\section{Terms of development of small business in Ukraine}

In Ukraine, small businesses are developed in the adverse conditions of the market economy. This process is dogged by massive problems. Small businesses are established and have some support, but the competitive entrepreneurial type of economic management in small business has not been created yet.

The current state of the national economic development in terms of ensuring the stabilization processes clearly shows that its main priority is the sustainable development of small businesses. As the experience of advanced economies shows, the urgency of food security is alleviated under the efficient operation of the agri-food sphere.

The accelerated dynamics of changes requires a prompt and adequate reaction from the Ukrainian society. Joining efforts should be aimed at minimizing adverse effects and maximizing benefits from the deepening of economic integration. Such an outcome can be achieved only through the creation of the functional economic system on the principles of sustainable development. A special place in these processes is given to small businesses.

The main goal of transformations under the sustainable development is the formation of an effective manager owner. The establishment of a new organizational and private model of the production organization objectively requires new approaches to the structure of financial performance of small businesses in Ukraine. The solution to the issues raised requires a constant search for the ways of expedient and appropriate operation of small businesses of Ukraine. This is required for business entities to be provided with the opportunity to ensure a continuous process of the product manufacturing and sales, to promptly pay for their obligations, and to freely make use of their own and borrowed capital.

The development of small businesses in Ukraine constitutes the development that meets the needs of the current generation and does not harm the ability of future generations to meet their needs by providing the interaction of economic, social, and environmental spheres. The stable development of small businesses is of exceptional social importance that is conditioned by an uncontested role in ensuring food security of the country.

Small business supports any scope of activities: industrial, commercial, insurance, etc. Therefore, small business is considered to be the leading sector of the economy to ensure the reliability, efficiency, and flexibility of the country's domestic market. It is important to emphasize that the domestic market depends primarily on the social and economic development of each state. Thus, without small business 
society and economy have no opportunity either to develop or to exist.

The state of the small business development in recent years indicates a steady trend towards the growth of this sector of the economy. Peculiarities of small business enable to assert that it is characterized by such features as independence of action, opportunity for more flexible and operative decisions, adjustment to the peculiarities of local conditions, strong sympathies among the population, low operational costs, chances of a quick material success, long-term benefits, opportunities to combine several professions, etc. All these features enable small businesses to occupy a ranking place in the economic structure of Ukraine.

Recently, the government has implemented several programs to support small business, the primary objectives of which are to ensure the development and assistance of small business. But despite this fact and the fact that small business is very important, its development and possibilities in Ukraine fail to reach a high point. Accordingly, the indicators of the small business development for many years remain quite low in comparison with other more economically developed countries.

The factors, which adversely affect the development of small business in Ukraine, are a general decline in the domestic commodity production, price advance, inflation, low level of the population solvency, corruption, etc.

One of the main disadvantages of small business in Ukraine is its uneven distribution across the country. Small businesses are mostly spread out in Kyiv, Kharkiv,
Odesa. They account for almost a third of all businesses that are engaged in food production and trade.

According to many experts, the main directions of further development of small business in Ukraine in the short term are: the formation of appropriate legislative framework conducive to the small business development; the improvement of financial and credit support; the provision of the material and technical, and innovative conditions for the development of small businesses; the information and staffing support for business; the promotion of foreign economic activities of small businesses. The formation of appropriate legislative framework conducive to the small business development requires, first and foremost, the provision of legal guarantees to ensure the freedom and protection of private property; the development of effective legislation and regulations aimed at encouraging small businesses; the elimination of legal inconsistencies and repeal of provisions that impede the development of a private initiative. Today, the most urgent problems are the development of new and improvement of existing laws and regulations on determining clear approaches to the property and forms of its protection; the creation of more favourable tax, investment, innovation, and pricing regimes for small businesses; the adjustment of the mechanisms of state regulation and control of entrepreneurial activity.

The peculiarities of its development in Ukraine, namely, the strengths and opportunities, as well as the main factors and threats that slow down the development of small business in Ukraine at the stage of its operation, have been determined with the application of the SWOT analysis of small business (Figure 1).

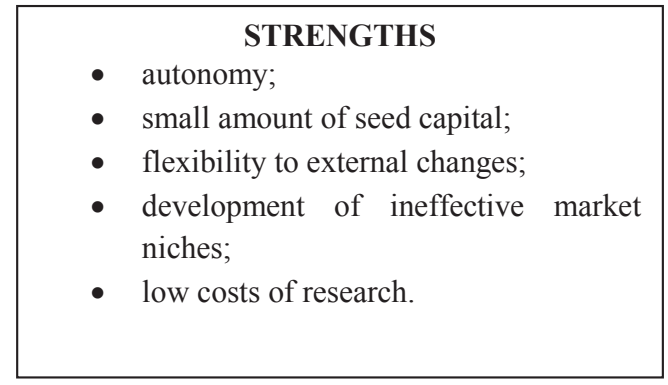

\section{WEAKNESSES}

- dependence on the unstable economic and political situation in the country;

- restricted access to external financing;

- sales market locality;

- profit instability;

- insufficient information support;

- $\quad$ staff insecurity

Figure 1. SWOT analysis of small business in Ukraine Source: developed by the authors

\section{OPPORTUNITIES}

- ability to occupy any market niche;

- growth, transition to big business;

- provision of employees of different age groups with the employment opportunities.

\section{THREATS}

- bankruptcy threat;

- difficulties with strategic planning;

- low consumer purchasing power;

- complexity and inconsistency of legislation (especially, tax);

- corruption overgrowth. 
The new job formation, bona fide competition, rapid saturation of the market with goods and services, and innovation occur in the Ukrainian domestic market due to small business. According to the data of economic sources, in Ukraine, the sphere of material production employs more than $87.5 \%$ of the labour force, and only $12.5 \%$ works in the service sector.

The analysis of foreign experience makes it possible to take a fresh look at the prospects for the small business development in Ukraine. Thus, since the 1990s, the share of small business in all industrialized countries has been substantial enough. In Japan and France, 99\% of all enterprises have been referred to small businesses. The degree of the small business development directly characterizes the degree of the state economy's development as a whole. The development of small business in the West occur at an even greater rate as governments pay a considerable attention to small businesses, and facilitate their development at the national level. In most countries, small business represents the middle class, which is the basis for sustainable economic development.

The economic analysis of business activities and evaluation of the economic performance of small businesses in the market conditions are based on the systematic approach, which is characterized by the comprehensive assessment of multifaceted factors, the targeted approach to their study with the aim of improving the performance of small businesses.

As the result of the research conducted, it has been established that the main stage, by which business may be marked as successful, efficient, and profitable, is the stage of its development and operation, which is characterized, according to the Doing Business ranking, by such criteria as tax payment, lending, investors' interest protection, contract performance.

The results of the SWOT analysis show that small businesses compared to other business entities have significant advantages and opportunities, among which flexibility and ability to occupy any market niche are the most important. However, there are a number of weaknesses and threats that, in comparison with the European small enterprises, are wide enough.

Thus, the main drawback of small business in Ukraine is a restricted access to the external financial resources, locality of sales markets and lack of adequate government support (especially, in the taxation sphere). From this perspective, the state regulation and promotion of small business should be aimed at levelling the impact of its drawbacks while turning them into potential opportunities.

The analysis of the general environment and trends in the sphere of small business regulation shows that the most important factor of limitation of the small business development is the significant administrative and tax pressure.

The fiscal policy of Ukraine plays a significant role in the small business promotion, which provides for a reduced tax rate, an effective system of discounts in payment of overdue loans, etc.

In Ukraine, the number of tax payments is 5 per year (after the entry into force of the amendments to the Tax Code dated December 24, 2015) (Pihnyak, 2014), and 350 hours are spent on their payment, while the total tax burden is $52.2 \%$. It is important to focus on individual programs aimed at promoting small business. It is expedient to provide small business with support in the form of consultations on the financing management and marketing. The study conducted gives grounds to assert that one of the few achievements of the national tax policy is the introduction of the simplified taxation system of small businesses.

\section{The need for state support for small businesses}

According to the Law of Ukraine "OnDevelopmentand State Support of Small and Medium Entrepreneurship in Ukraine", small businesses in Ukraine include physical and legal entities of any organizational and legal form and form of business ownership, the average number of employees of which during the reporting period (calendar year) does not exceed 50 persons, and annual income from any activity does not exceed the amount equivalent to 10 million euro, determined at the average exchange rate of the National Bank of Ukraine (in 2015, about 242 million UAH). As of today, the most important form of state support for small business in Ukraine is the simplified tax system, which provides for the replacement of taxes and fees established by the state with the payment of a single tax and the application of a simplified form of accounting and reporting.

To improve the efficiency of the established system of state support for small business, it is essential to carry out the following measures:

to work out the financial strategy to attract the Ukrainian and international banking capital for ensuring the development of small business in Ukraine;

- toform theleasingsystemas one ofthemostchallenging opportunities for the creation and development of the production base of small and medium business;

- to promote the development of the foreign economic activity of small businesses;

- to carry out the training and retraining of staff for work in small businesses;

- to create conditions for the effective development of entrepreneurship by creating a favourable infrastructure; - to improve the information, and regulatory and legal support for the entrepreneurial activity in the sphere of small business;

- to improve the quality of advertising and exhibition, and publishing activities in this sphere;

- to develop the innovation activities of business entities, to promote the development of new technologies and inventions. 
Financial and credit support for small businesses in Ukraine is of prime importance nowadays. The state policy regarding financial support should be aimed at the establishment of a developed network of financial institutions, insurance companies, investment and insurance funds; the development of reciprocal lending and insurance companies; the development and implementation of the system of incentives of commercial banks that would provide preferential loans to small businesses.

Informational support involves the creation of a single information space, the systematization and harmonization of indicators and documents. The automation of management activities is the objective process, which should cover the industry as a whole. The basis of these activities is to create the environment, which should cover and unite the information, telecommunication, software provision, information technologies etc. that will contribute to a qualitatively new level of day-to-day operational work and the analysis of prospects for activities in general.

The lack of own sources of financing of fixed capital renovation, unavailable services of banking institutions and other conditions require the development of the productive capacity recovery mechanisms, which are non-traditional for small businesses.

The issues on the intensification of the investment activities of small businesses deserve attention when justifying the main trends of their development. The solution to the methodical problems of the rational implementation of the investment process in the region that is based on programs and strategic rationale for the regional investment projects and the establishment of the mechanism for their effective operation is of vital importance at the regional level.

Ensuring the production competitiveness requires the implementation of innovations, as well as the upgrade of technological equipment, which would make it possible to produce high-technology products. The fulfilment of this task is extremely risky because it requires a significant amount of investments and constant study of consumer demand. We have performed the analysis of investment activities of the agricultural sector in connection with the availability of numerous institutional constraints and administrative barriers. The government in the process of formation of innovative and investment activities assumes the regulatory functions.

\section{The foreign experience}

The foreign experience shows that a prerequisite for success in the small business development is a comprehensive and sustained government support. In the crisis conditions of the economic development, it is the government support for small business that could lead to the improvement in the economic situation both in regions and the country as a whole. Today, the government connects its hopes for rapid positive structural changes in the economy, the recovery from the economic crisis and creation of conditions for economic growth with small- and medium-size business. As evidenced by recent global trends, it is the targeted government support for enterprises, particularly small businesses, that is the most important feature of a modern policy in the field of entrepreneurship. In Ukraine, despite the declared support for small business made by the state, its influence on the process of the small business formation is clearly insufficient.

The important feature of the development and state regulation of small business in Ukraine is the lack of emphasis on the social significance of small business, its ability to rapidly expand the demand for the labour force. Small business is considered in the framework of the state policy only through the lens of economics. The continuation of this problem is the derivative problems of the excessive government regulation, numerous administrative barriers and low level of executive discipline in state authorities worsened by a high level of corruption.

The issues concerning the organization of insurance activities of small businesses have been and are studied in details on the pages of periodicals and special literature. Insurance provides the reliable protection of property interests of entrepreneurs and population in case of losses caused by fire, natural disaster, technological accidents, transport accidents and many other unforeseen circumstances. Insurance has been well proven as a form of accumulation of personal savings to solve the social problems of the population (healthcare, pensions, education etc.). In recent years, insurance is widely used to cover any third party liability. The proposed ways and directions of the development of the Ukrainian insurance market, in our opinion, will enable to accelerate the creation of an adequate insurance market as the objective attribute of the market economy and to facilitate the restoration of confidence of policyholders in insurers.

Today, a private entrepreneur, despite a large number of regulatory acts that would regulate this type of activities, is in a very difficult position. The creation of voluntary associations of private entrepreneurs protects small businesses in their competition with monopolistic structures in both domestic and foreign markets of output sales.

The efficient tool to facilitate the effective development of small businesses is the infrastructure of its support, due to which the specific organizational and economic environment is formed for the promotion of entrepreneurship and rapid adaptation of small businesses to market conditions. At present, the expedient is the policy of support for a small business, the main objective of which is balancing the interests of the state and business, the provision of the best conditions for entrepreneurial activities, 
increase in the competitiveness of small businesses. Small businesses are more resilient to external changes. Given a small number of employees quickly adjusting to market changes, small business may turn out to be the important basis, on which a pivot towards the effective business processes will begin. These enterprises provide the socially vulnerable sections of the population, in particular, young people, women, immigrants, etc., with the possibility of employment. They also gain experience, knowledge, and enhance their career and self-fulfilment at these enterprises. It is advisable to take into account a number of advantages of this business, namely: low capital intensity and, therefore, an easy access of the population, a large number of enterprises that enables to promptly establish the production of various goods and services, mobility in the market and in the sphere of technologies that promotes the rapid development of entrepreneurship, the ability to hire additional labour force, the absence of bureaucracy in management, minor adverse environmental impacts.

\section{The main problems hampering the development of small business}

The small business development has been facilitated by the fact that it is recognized by the state as one of the most important elements of the system of national economy that requires special attention and support.

The main problems constraining the development of small business are:

- imperfection of the tax system;

- instability of budgetary financing of regional programs of small business support;

- immaturity of mechanisms of financial and credit support and risk insurance of small enterprises; lack of self-financing mechanisms;

- restriction of the small businesses' access to productive capacities and property of the enterprises being restructured;

- lack of reliable social protection and security of entrepreneurs;

- organizational problems of interaction of small business with market and government agencies;

- administrative barriers to the small business development.

In this regard, we believe that the small business development is based on the system interaction of the institute of entrepreneurship, information, and the factors that determine the direction of its operation. In the economy of the region, this includes an imperfect tax system; instability of budgetary financing of regional programs of small business support; immaturity of mechanisms of financial and credit support and risk insurance of small enterprises; lack of self-financing mechanisms (credit unions, reciprocal insurance companies); restriction of access of small enterprises to productive capacities and property of the enterprises being restructured. This development is conditioned by the transformation processes of the Ukrainian economy that have shaped the current state of small businesses.

The accelerated development of entrepreneurship in Ukraine is possible on the basis of the consistent state policy on decentralization of economic management and improvement of market mechanisms and local power brokers.

The main government functions promoting entrepreneurial activities that contribute to its rapid development include:

- creation of the conditions for training competitive specialists;

- creation of the mechanisms for entrepreneurial support and financing;

- implementation of the measures for the promotion and development of regional market infrastructure.

Summarizing the positive and negative aspects of the development of small businesses, it can be noted that by quantitative estimates, the formation of this economic sector is a strategic pathway for further development of Ukraine's economy.

\section{Conclusions}

The development of small business in Ukraine is a significant but underutilized reserve of economic growth. Its activation is one of the key priorities of the regulation of the social and economic development of the Ukrainian economy. The economic, social, and environmental dimensions of the sustainable development have a complex nature that determines the need for a nonlinear approach to ensuring their harmonious combination. The environmental dimension of sustainable development of the agri-food system, which unites the manufacture and processing of products and the food market implies a stable economic growth of small businesses in the sphere of product processing. The introduction of these proposals will facilitate the adoption of scientifically grounded managerial decisions and further development of small business in Ukraine.

According to the research results, it is expedient to carry out further development of small businesses in Ukraine, in our opinion, in the following directions:

- formation of own markets of product sales;

- introduction of innovative technologies of product manufacture;

- implementation of investment projects on the acquisition of machinery and equipment under the lease; - making part of investments in the development of technology and production infrastructure;

- creation of voluntary associations of private entrepreneurs;

- increase in volumes of direct investment of small business at the expense of own funds and loans;

- creation of risk insurance fund and enhanced cooperation with insurance companies. 
When studying the approaches of state regulation and small business promotion in Ukraine under the tax policy formation, we revealed its strengths and weaknesses, as well as the opportunities for further development, and the threats inhibiting it. Recommendations for improving the business development have been made on the basis of the study of state regulation of small business operation.

Most of the focus is placed on the issues of stirring up investment activity in the justification of the basic trends in the development of small businesses. The measures aimed at attracting financial resources to make investments at the regional level that will contribute to the development and establishment of small businesses have been proposed. In this regard, it is recommended to analyse the factors of regional investment prospects in Ukraine.

The article focuses on the role of government in promoting entrepreneurial activity, the interaction of entrepreneurship with other structural elements of society. The study has made it clear that the issues of the formation and operation of the small business, as well as workflow management and business administration at these enterprises, are controversial.
Pride of place is given to the problems of operation of small businesses, which are more resilient to external changes. Given a small number of employees quickly adjusting to market changes, a small business may turn out to be the important basis, on which a pivot towards the effective business processes will begin. These enterprises provide the socially vulnerable sections of the population with the possibility of employment.

The article focuses on the main arguments in favour of the features of the organization and operation of the insurance activity of small businesses.

The main direction of future activities of small business is to create conditions for the effective implementation of entrepreneurial activities of business entities, to overcome any difficulties and solve problems related to the lack of knowledge and experience on doing business, to provide access to loans and required information, to facilitate the creation of new jobs, to overcome disparities in the regional economic development, to increase export capacities of small enterprises, growth of production and its restructuring, to facilitate an access of small business to modern innovative technologies.

\section{References:}

Bryukhovetsky I.M. (2001). Basics of entrepreneurial activity and agribusiness: Publishing House "Kozatsky Val", pp. 304-345.

Kondratenko M.B. (2015). Tax burden and ways of its optimization in Ukraine [text]: Author's abstract, pp. 3-20.

Law of Ukraine "On Development and State Support of Small and Medium Enterprises in Ukraine" (2012). No. 4618-VI dated March 22, 2012. Retrieved from: http://zakon5.rada. gov. ua/laws/show/4618-17

Mikhailov M.G., Poliatykina L.I. \& Slavkova O.P. (2008). Organization of accounting in small business enterprises, pp. 241-255.

Pavlov O.I. (2012). Sustainable development and security of the agro-food sector of Ukraine in the face of globalization of challenges: Monograph, pp. 207-214.

Pihnyak T.A. (2014). The world experience of public administration in the development of small business and the possibility of its adaptation in Ukraine: Monograph, pp. 123-146.

Poliatykina L.I. (2016). Methodological and accounting-analytical support of sustainable development of small business enterprises: Monograph, pp. 47-140.

Poliatykina L.I. (2018). Modern Trends to Promote Sustainable Development of Small Business Enterprises. Eurasian Academic Research Journal (ISSN: 1829-4863), Multilanguage Science Journal, 1(19), $138-142$.

Poliatykin S.O. (2018). Features of innovation and investment activity in foreign countries: Economic and law paradigm of modern society, 1, 39-44.

The Tax Code of Ukraine No. 2755-VI from 02.12.2010. Retrieved from: http://zakon5.rada.gov.ua/laws/ show/2755-17 